\title{
XV. Intermittent lightning-flashes
}

\author{
H. H. Hoffert D.Sc. A.R.S.M.
}

To cite this article: H. H. Hoffert D.Sc. A.R.S.M. (1889) XV. Intermittent lightning-flashes, Philosophical Magazine Series 5, 28:171, 106-109, DOI: 10.1080/14786448908619838

To link to this article: http://dx.doi.org/10.1080/14786448908619838

$$
\text { 曲 Published online: } 08 \text { May } 2009 .
$$

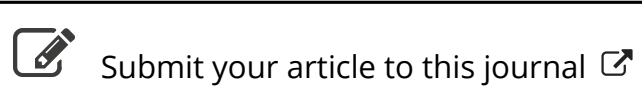

\footnotetext{
Џll Article views: 2
}

Q View related articles $\sqsubset$ 
Experiments Nos. 1, 2, 3, 6, 14 $\mathrm{A}^{\prime}, 17 \mathrm{~A}$, and 22 were interrupted by divers accidents and never completed; in No. 19 there is confusion in the notes, making the sign of the deflexion doubtful ; Nos. 21, 23, and 24 give values of $\rho$ from 2 per cent. to 10 per cent. out, due to some error in the record of resistances used. This accounts for all the experiments begun.

The average of all the above is .98622 ; without No. 27 which differs about twice as much from the mean as any other observation, the average is 98634 . The great divergence of No. 27 is in itself reason enough for giving it less weight; but in addition, the chronograph sheet shows that the speed here was very irregular, increasing, decreasing, and increasing again; this is the only occurrence of such irregularity. Therefore, giving it about one third weight, we find as the most probable value

1 B.A. Unit $=.9863 \mathrm{ohm}$.

A determination of the "Mercury Unit" was recently made by Messrs. Hutchinson and Wilkes (Johns Hopkins University Circulars, May 1889; Phil. Mag. July 1889) who found the value to be 95341 . Taking this with the above number for the B.A. unit, we have as the length of the mercury column corresponding to the ohm,

$106 \cdot 34$ centims.

XV. Intermittent Lightning-Flashes. By H. H. HOFFERT, D.Sc., A.R.S.M., Demonstrator of Physics at the Normal School of Science and Royal School of Mines*

[Plate IV.]

THE storm which passed over London on the evening of $J$ une 6 th afforded an unusually favourable opportunity for observations, both with and without the aid of the camera, on the character of lightning-flushes, and for determining the causes of some of the curious effects noticed by previous observers.

While watching the storm from my house in Ealing I could in several instances distinctly perceive a flickering appearance in a discharge, and in one particular case the repetitions were at least 5 or 6 in number, just sufficiently slow for the eye to detest the variations in brightness without removing the impression of one single flash. Other observers

* Communicated by the Physical Society : read June 8, 1889. 
with whom I have since spoken have informed me that they had observed a similar effect, and that in some instances flashes, following as nearly as could be seen in the same path, were separated by an appreciable interval, often of several seconds' duration. Photographs of lightning have frequently been obtained showing banded, ribbon, or double flashes; but, so far as I am aware, these have not been of so decided a nature as to remove doubts whether the appearances could not be ascribed to the effects of halation by reflexion from the back of the negative, or to blurring from the photograph having been taken through the glass of a window, or to some other similar cause. I was therefore anxious to obtain some decisive evidence of the repetition of the flashes, and as my friend Mr. G. J. Snelus was at my suggestion attempting to obtain some photographs of the lightning, I joined him, and he kindly placed his camera and some plates at my disposal.

The rain having ceased for the moment, I was able to go out on to a balcony and thus get a good view of the storm, which had now approached quite close and seemed to surround us. The camera was held in the hand and pointed towards the north-east, where, about half a mile away, numerous brilliant flashes were occurring. The cap of the camera was taken off, and then the camera was moved in a horizontal plane about the lens as a centre at the rate of about once to and fro in three quarters of a second, until a flash was observed in the direction in which it was pointed, when the cap was at once replaced. The duration of the exposure of the plate was about half a minute. The camera was of quarter-plate size, the plates were Ilford rapid, and the lens, which was a rapid rectilinear, was used with full aperture $(i / 8)$.

I hoped, by having the camera moving, to be able to separate the successive components of the flashes, and in this I was fortunately successful. In fig. 1 (Pl. IV.) is a reproduction of one of the photographs obtained, and on it can be seen two triple flashes (I., II., III., and IV., V., VI.), and one double flash (VII. and VIII.).

During the interval that the plate was exposed the illumination of the sky from flashes out of the line of view, or behind clouds, produced the glare seen in the centre and upper part of the photograph, and some faint flashes which were noticed were probably the cause of the streaks seen in fig. 2 at $o, p$, and $r$.

A careful examination of the photograph reveals many interesting features. The three successive flashes I., II., IIII. are identical in form. If the negative be placed over a print so that either of the three lines on the negative lies over 
Phil. Mag. S. 5. Vol. 28. Pl. IV. INTERMItTent Lightning Flashes.

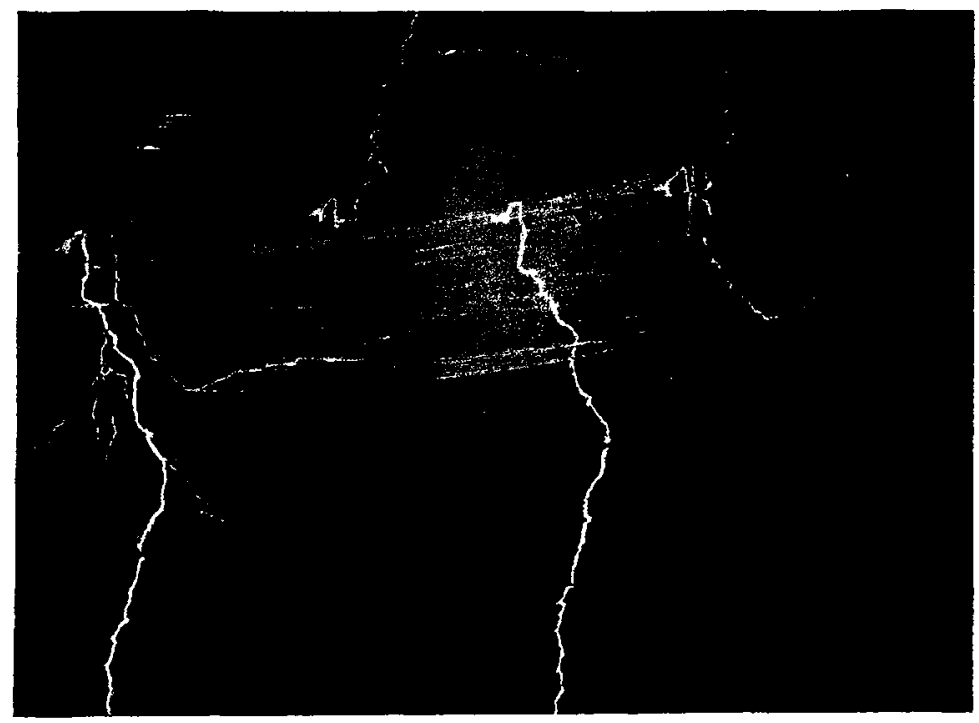

Fig. I.

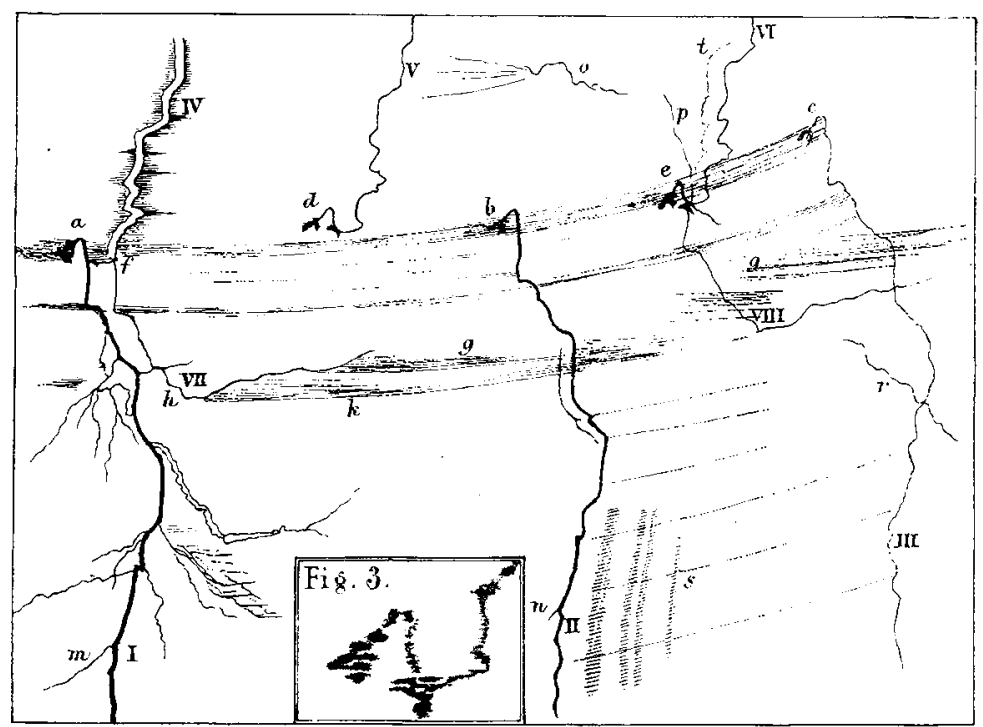

Fig. 2

Mintern Bros. Bth. 
either of those on the print, the coincidence is seen to be exact even to the smallest irregularities. Nevertheless, of all the branch-flashes which spread out from I. only a small trace exists at $n$ in II., and none whatever in III. Sweeping across the photograph and connecting corresponding points in the successive flashes are streaks of light, showing that a very considerable residual illumination remains between the discharges. These streaks are especially well marked between the components of the double flash VII., VIII., and are also very bright along the path of the head of flash I. They are not always present; for in another photograph obtained upon a moving plate by Mr. Snelus, in which a flash is reduplicated, there is no trace of them, the flashes being quite sharp and distinct. The streaks commence abruptly with one discharge and end abruptly with another. Their extension to the left of I. was probably due to the camera not having quite reached the end of its swing. Where they are brightest there is in all cases a swelling at the part of the flash where they start.

At the upper left-hand corner there is a curious dark flash with bright edges and short luminous streaks. The form of this dark flash is exactly reproduced in the two bright flashes V. and VI. Dark flashes are frequently met with in photographs of lightning, and have been usually ascribed to reversal of the image by overexposure; but 1 do not think this explanation applies in the present case, both on account of the appearance which the dark flash presents, and also because as far as I can recollect the brilliant downward flash I. appeared to the eye much the brightest of those that occurred while the plate was exposed. There is a similar but less distinct dark gap to the left of VI. ; and to the right of II. are three or four faint bands parallel to it and following its sinuosities. These all seem to be due to variations in brightness in the luminous streaks, which are thus shown to be electrical and not phosphorescent in character.

When carefully compared, the forms and positions of the flashes I. to VIII. are found to present such agreement as to show that they must have formed a system of discharges closely connected together. If $\mathrm{V}$. be placed over IV. so as to coincide with its left-hand border, the portion $d$ exactly coincides in form and position with the portion $a$ of I., and both $a$ and $d$ terminate in a curious bifurcated enlargement which, when examined with a lens, shows a beaded appearance, roughly sketched in fig. 3. This coincidence of form and position would be difficult to account for if I. and IV. were independent flashes not occurring at the same time. It is 
evident, however, that the series I., II., III. cannot have occurred during the same sweep of the plate as IV., V., VI., since the curve joining $a, b, c$ is concave upwards, while that joining $a, d, e$ is concave downwards. The flashes VII., VIII. seem also to have formed part of the same system of discharges, for the part of VII. from $f$ to just above $h$ is coincident with the upper portion of I., while the luminous streaks extending between VII. and VIII. agree in their directions with the curves joining $a, b, c$ and $a, d, e$, those at $g$ being parallel to the line joining $d$ and $e$, and those at $k$ following nearly but not exactly the line of $a, b, c$. There is thus afforded some clue to the determination of the prder of the discharges, and I think the order was probably as follows:-VII., VIII., VI., V., IV., I., II., III., the first two occurring during one sweep of the camera ; VI., V., IV. during the backward sweep; and I., II., III. in the next onward sweep. There must thus have been an interval of a little over a second between the first and last discharge, for the motion of the camera was at about the rate of three quarters of a second for a complete swing to and fro. The interval between the successive discharges was, therefore, between the fifth and tenth of a second. Had it been much longer the flash would have presented to the eye a flickering appearance.

Whatever be the explanation of some of the effects noticed above, it is evident that a lightning flash has not the simple instantaneous character formerly supposed; but that it consists of a varying number of successive discharges following one another in the same path at intervals which may in some cases be comparatively long.

Note.-Since the above was written I have had an opportunity of inspecting the photographs of banded, ribbon, and curtain lightning collected by the Royal Meteorological Society. There is, I think, no doubt that the explanation of these is afforded by the multiple flashes and luminous streaks noticed above. It is noteworthy that they were always obtained with a camera held either in the hand or in such a way as to render motion probable.

Science Schools, S. Kensington.

Phil. Mag. S. 5. Vol. 28. No. 171. August 1889. K 